\title{
Naturally triggered persistent deep slab avalanches in western Canada Part I: avalanche characteristics and weather trends from weather stations
}

\author{
MICHAEL CONLAN, BRUCE JAMIESON \\ Department of Civil Engineering, University of Calgary, Alberta, Canada \\ Correspondence: Michael Conlan <mike.conlan@ucalgary.com>
}

\begin{abstract}
A database of difficult-to-forecast natural persistent deep slab avalanches was analyzed to determine thresholds for parameters that contribute to their release in western Canada. The database included avalanche observations and weather station data. The avalanches were grouped based on their primary cause-of-release, either precipitation loading, wind loading, solar warming or air temperature warming using a multivariate classification tree, which first split using a solar warming parameter. The precipitation group had a median $24 \mathrm{~h}$ snowfall of $15 \mathrm{~cm}$ and $3 \mathrm{~d}$ snowfall of $38 \mathrm{~cm}$ at weather stations, mostly at or below treeline. These amounts were likely closer between $20-30$ and $50-80 \mathrm{~cm}$ at alpine start zones. The wind loading group experienced the most wind-transported snow potential. The solar warming group had predicted solar warming of $5.2^{\circ} \mathrm{C}, 10 \mathrm{~cm}$ into the snowpack, on the days of release. The air temperature warming group experienced the highest median maximum air temperature $\left(5^{\circ} \mathrm{C}\right)$ on the days of release. These thresholds may be useful to forecast the likelihood of similar avalanches with experienced-based forecasting or with decision aids, although many false alarms are possible. A companion paper, Part II, relates weather model data to avalanche occurrences.
\end{abstract}

KEYWORDS: avalanches, classification tree, forecasting, persistent weak layer, weather station

\section{INTRODUCTION}

Weather contributes to the release of natural avalanches, including difficult-to-forecast persistent deep slab avalanches that are naturally triggered. The release of a persistent slab begins with the failure of the underlying persistent weak layer. One of the most important of the causal processes is related to an increase in the overlying load from precipitation or wind-transported snow. This load increases the strain rate and stress intensity on the persistent weak layer, causing brittle fracture if its fracture toughness is exceeded (Schweizer and others, 2004). Another important process is associated with the temperature increase within snowpack because of increases in air temperature or incoming shortwave radiation. In these cases, the strain and strain rate both increase in the upper snowpack (Schweizer and others, 2003). This combination may critically strain the persistent weak layer in shallow portions of the snowpack, which can release a deep slab that is spatially variable in thickness.

Weather in mountainous terrain is complex and has been widely studied. The large variations in topography and vegetation associated with mountains produce microclimates that affect the snow cover differently, depending on aspect and elevation (Meiman, 1968), producing a spatially heterogeneous snowpack, often including persistent weak layers. Surface hoar generally forms during clear, cool nights with low wind velocities (Hachikubo and Akitaya, 1997). Faceted grains and depth hoar are typically formed in shallow snowpack areas where high temperature gradients develop from cold air temperatures (de Quervain, 1958; Akitaya, 1967). Melt-freeze crusts can be associated with persistent weak layers and can be caused by rain events on any aspect, warm temperatures on any aspect or strong incoming shortwave radiation on sun-exposed aspects during days with minimal cloud cover (Jamieson, 2006). Such crusts can have a poor bond with the overlying or underlying snow layer and can be the cause of poorly bonded faceted grains either above or below the crust. Failures in these persistent weak layers can lead to persistent deep slab avalanches.

Forecasting deep slab avalanches associated with persistent weak layers is often difficult (Jamieson and others, 2001) and forecasting techniques applied to smaller avalanches are not adequate for deep slab avalanches (Föhn and others, 2002). Deep slab avalanches are often unexpected, as they typically release after the period of high avalanche hazard for the associated weak layer. Deeply buried weak layers are less influenced by the weather than shallow layers because of the large depth to the weak layer. High amounts of overburden load or strong temperature fluctuations are generally required to naturally trigger such avalanches. However, threshold values of certain weather parameters that may contribute to the release of persistent deep slab avalanches are not well defined for the mountains of western Canada.

Important weather parameters for avalanching include precipitation amounts, precipitation rates, wind speeds, wind directions, temperature variations and sky cover (Atwater, 1954; Perla, 1970; Judson and Erickson, 1973; Ferguson and others, 1990; McClung and Tweedy, 1993; McClung and Schweizer, 1999; Schweizer and others, 2003; Jomelli and others, 2007). Jóhannesson and Jónsson (1996) found that precipitation amounts $\sim 10-30 \mathrm{~mm}$ over a 3 or $4 \mathrm{~d}$ period and $10 \mathrm{~min}$ wind speeds of $40-80$ knots (75-150 $\mathrm{km} \mathrm{h}^{-1}$ ) caused large avalanche cycles in a region of Iceland. Schweizer and others (2009) also used new 
snow amounts for determining the return period of large avalanches in Switzerland, although threshold values were not useful because of high false alarm ratios. The false alarm ratio indicates the reliability of a parameter threshold by determining the number of non-occurrences associated with it.

Bradley (1970) and Fitzharris (1987) found that winters with many deep slab avalanches started with low temperatures in early winter months, followed by high amounts of precipitation. Schneebeli and others (1997) and Stoffel and others (1998) determined that threshold values of $50 \mathrm{~cm}$ of snowfall over a $3 \mathrm{~d}$ period triggered many large and destructive avalanches in Switzerland. Föhn and others (2002) also found that precipitation was the strongest parameter for forecasting deep slab avalanches. Further, Savage (2006) found important weather factors to be multi-day precipitation amounts and strong prevailing winds that led to loading from wind-transported snow.

Both univariate and multivariate approaches have been used to predict avalanches. Bois and others (1975) used discriminant analysis to group days with avalanches and days without, using numerous weather parameters. Davis and others (1999) used classification and regression trees to determine weather factors that explained avalanche activity. Classification trees created by Jones and Jamieson (2001), Hendrikx and others (2005), and Hendrikx and others (2014) were successful at predicting days with avalanches $67 \%$, between 78 and $85 \%$, and between 77 and $94 \%$ of cases, respectively. Marienthal and others (2014) also created classification trees, but used them to identify important meteorological variables associated with winters of high avalanche activity. They found that few and abrupt periods of loading over the first months of the winter season led to an increased amount of late-season deep slab avalanches. Avalanche forecasters can use the results of classification trees. For example, the values of the splits in the trees could be used as thresholds for a forecasting region, if the tree was created with data representative of the region.

Improved forecasting for persistent deep slab avalanches in western Canada has been a research focus for the past two decades. Jamieson and others (2001) studied naturally triggered deep slab avalanches in the Columbia Mountains of western Canada and found that the highest meteorological ranked predictors were accumulated snowfall over the preceding several days and air temperature changes over the preceding 4-5 d. Tracz (2012) analyzed various forms of precipitation, temperature and wind speed, and found the most significant variables that discriminated days with deep slab avalanches from those without to be antecedent precipitation variables followed by temperature variables. He found high false alarm ratios for threshold values. Conlan and others (2014) found comparable threshold precipitation values from weather stations near persistent deep slab avalanches. They proposed that separating deep slab avalanches by release mechanisms could provide better results. Conlan and Jamieson (2013) grouped 11 naturally triggered persistent deep slab avalanches by primary causes-of-release and compared loading and temperature parameters. Natural avalanches that likely released from rapid mass loading experienced high cumulative precipitation and wind loading potential amounts whereas avalanches that likely released from solar warming did not experience high amounts of precipitation, wind loading, or air temperature warming.

The objective of this study was to observe difficult-toforecast persistent deep slab avalanches and summarize terrain and snowpack characteristics. We then determined threshold values of certain weather parameters associated with the occurrence of persistent deep slab avalanches, which may be used by avalanche forecasters in western Canada and other locations with similar snow climates. This study focuses on weather data obtained from weather stations. Since weather data from a nearby weather station are sometimes unavailable to a forecasting operation, Part II of the study examines similar weather parameters from numerical weather prediction models and compares the data sources (Conlan and Jamieson, 2016).

\section{METHODS AND DATA}

Data were obtained from the Information Exchange (InfoEx), a compilation of daily avalanche, snowpack, terrain and weather observations from 100 avalanche safety operations in Canada, organized by the Canadian Avalanche Association. All avalanche and weather data were obtained for the years 2006 to 2014. The InfoEx dataset was first filtered for trigger type. Natural releases were separated and subsequently grouped by the burial date of the failure layer. Assigning a date to persistent weak layers and interfaces facilitates communication between avalanche forecasting programs in western Canada. For example, a surface hoar layer that is buried on 17 January is classified as $\mathrm{SH} 17$ January (CAA, 2014). Avalanches were not filtered for destructive size because this is largely a factor of terrain. The avalanches within each failure layer group were analyzed to identify those that occurred outside of prominent periods of avalanching for each particular persistent weak layers (i.e. an avalanche cycle). The avalanches outside avalanche cycles were classified as difficult-to-forecast persistent deep slab avalanches (e.g. Fig. 1). These avalanches were all in the oldest $10 \%$ of the distribution of occurrences for each respective failure layer. This method selected 88 avalanches. For avalanches that released on failure layers that were not geographically widespread and not actively releasing, a

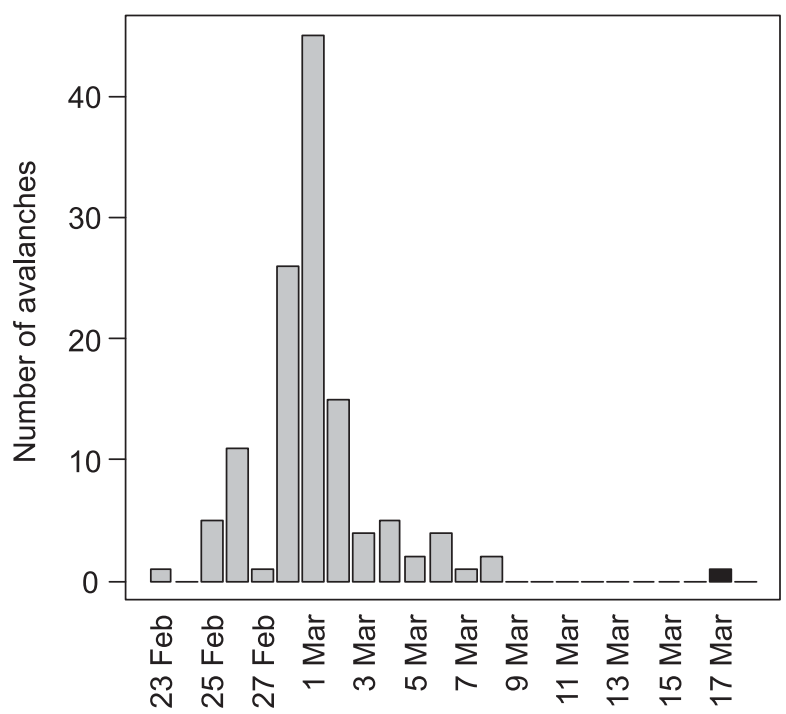

Fig. 1. Example of the distribution of natural avalanches that released on a persistent weak layer of surface hoar and faceted grains that formed and was buried in February 2011. The highlighted avalanche (black) was selected as a difficult-to-forecast deep slab avalanche because it was outside of a prominent avalanche cycle for that layer. 
threshold of $32 \mathrm{~d}$ was used, as this was the average length of time between weak layer development or burial and avalanche release for those releasing outside an avalanche cycle. This method selected 73 additional avalanches. In total, 161 difficult-to-forecast persistent deep slab avalanches that occurred in western Canada over the 8 a period were selected from the InfoEx dataset.

Within the difficult-to-forecast dataset, some avalanches were reported to have released because of loading from precipitation or wind-transported snow and some because of snow temperature variations from solar warming or air temperature warming. In our study, these weather trends that contributed to the releases are termed primary cause-ofrelease. For 22 of the 161 avalanches, the primary causeof-release was stated in the comments of the InfoEx records by avalanche professionals. An additional 16 naturally triggered avalanches with known primary causes-of-release were used to increase this subset, obtained from the study by Conlan and others (2014) and subsequent research.

Daily weather parameter values were obtained for each of the 161 avalanches for the day of its release and for the preceding $14 \mathrm{~d}$. The weather data were measured at weather stations - mostly at or below the treeline - for nearby avalanche safety operations. Data were most often manually observed once or twice per day. The weather parameters obtained included daily minimum and maximum air temperature, precipitation amounts, precipitation rate, average wind speed and direction and sky cover.

The weather parameters used in our study were classified into four general groups: precipitation loading, wind loading, solar warming and air temperature warming. Precipitation parameters included maximum precipitation rate for each day of release and cumulative snowfall amounts. Snow w.e. was not available from most operations so snowfall amounts in centimetres were used. Wind parameters included maximum wind speed for each day of release and potential cumulative wind loading amounts. Solar warming parameters included sky cover and a snowpack warming parameter on each day of release as well as its $1 \mathrm{~d}$ change. Air temperature warming parameters included maximum and minimum air temperature on the day of release and 1 $\mathrm{d}$ maximum and minimum air temperature changes. The parameters analyzed in this study are presented in Table 1.

Wind speed and direction were used to estimate the wind loading potential. The maximum recorded wind speed was used because the wind at the start zones was likely higher than those at the weather station. Following Föhn (1980), the wind snow loading potential $\left(\Delta H\right.$ in $\left.\mathrm{cm} \mathrm{d}^{-1}\right)$ was calculated:

$$
\Delta H=\frac{u^{3}}{125}
$$

where $u$ is the daily average wind speed $\left(\mathrm{m} \mathrm{s}^{-1}\right)$. To account for the difference between the wind direction and the start zone aspect in determining whether the slope was likely lee or windward, the following formula was applied to calculate the wind loading potential $(H)$ from transported snow $\left(\mathrm{cm} \mathrm{d}^{-1}\right)$ :

$$
H=-\Delta H \times \cos \left|\theta_{\mathrm{w}}-\theta_{\mathrm{asp}}\right|
$$

where $\theta_{\mathrm{w}}$ is the wind direction $\left(^{\circ}\right)$ and $\theta_{\text {asp }}$ is the average start zone aspect $\left(^{\circ}\right)$. This equation adds load for lee aspects (positive values) and removes snow for windward aspects (negative values). Cross loading from a perpendicular wind direction to the start zone angle is not accounted for in this equation, although it can be significant in bowls and gullies (e.g. Schirmer and others, 2011). This equation also ignores veering winds at ridge top and the presence or absence of a fetch, which can increase the amount of snow available for wind loading.

Based on daily maximum incoming shortwave radiation, potential solar warming $10 \mathrm{~cm}$ into dry snow was estimated with the regression model SWarm (Bakermans and

Table 1. Weather parameters used within this study. Precipitation, wind and sky cover data were obtained from weather stations for nearby

\begin{tabular}{|c|c|c|}
\hline Parameter name & Units & Description of parameter \\
\hline $24 \mathrm{~h}$ precipitation & cm snow & Observed $24 \mathrm{~h}$ snowfall on horizontal board at weather station on day of avalanche release \\
\hline$n$-day precipitation & $\mathrm{cm}$ snow & $\begin{array}{l}\text { Cumulative } n \text {-day snowfall starting on day of avalanche release, summed from daily observations. } n \text { is } \\
\text { between } 2 \text { and } 7\end{array}$ \\
\hline Maximum precipitation rate & $\begin{array}{l}\mathrm{cm} \text { snow } \\
\mathrm{h}^{-1}\end{array}$ & Maximum observed precipitation rate on day of avalanche release at weather station \\
\hline $24 \mathrm{~h}$ wind load & $\mathrm{cm}$ snow & $\begin{array}{l}\text { Calculated } 24 \mathrm{~h} \text { wind-transported snow from Conlan and Jamieson (2013). Observed wind speed and } \\
\text { direction at the weather station were used in conjunction with the start zone aspect }\end{array}$ \\
\hline n-day wind load & cm snow & Cumulative $n$-day wind-transported snow amounts, summed from daily calculations. $n$ is between 2 and 7 \\
\hline Maximum wind speed & $\mathrm{km} \mathrm{h}^{-1}$ & Maximum observed wind speed at weather station on day of avalanche release \\
\hline Sky cover & $\sim$ & $\begin{array}{l}\text { Observed sky cover on day of avalanche release. Values are: clear (1), few (2), scattered (3), broken (4), } \\
\text { overcast (5), obscured (6) }\end{array}$ \\
\hline SWarm & ${ }^{\circ} \mathrm{C}$ & $\begin{array}{l}\text { Modelled warming potential } 10 \mathrm{~cm} \text { into snowpack from incoming shortwave radiation on day of ava- } \\
\text { lanche release. Sky cover and precipitation data at the weather station were used in conjunction with the } \\
\text { start zone location, aspect and incline }\end{array}$ \\
\hline 1 d SWarm change & ${ }^{\circ} \mathrm{C}$ & $\begin{array}{l}\text { Calculated difference between the modelled solar warming on the day of the avalanche release and the } \\
\text { day before the release. Positive values indicate more potential warming on day of release }\end{array}$ \\
\hline Maximum temperature & ${ }^{\circ} \mathrm{C}$ & Maximum air temperature at weather station on day of avalanche release \\
\hline Minimum temperature & ${ }^{\circ} \mathrm{C}$ & Minimum air temperature at weather station on day of avalanche release \\
\hline $\begin{array}{l}1 \mathrm{~d} \text { maximum temperature } \\
\text { change }\end{array}$ & ${ }^{\circ} \mathrm{C}$ & $\begin{array}{l}\text { Calculated difference between the maximum air temperature during the day of the avalanche release and } \\
\text { the maximum air temperature the day before the release. Positive values indicate a warming trend }\end{array}$ \\
\hline $\begin{array}{l}1 \mathrm{~d} \text { minimum temperature } \\
\text { change }\end{array}$ & ${ }^{\circ} \mathrm{C}$ & $\begin{array}{l}\text { Calculated difference between the minimum air temperature during the day of the avalanche release and } \\
\text { the air minimum temperature the day before the release. Positive values indicate a warming trend }\end{array}$ \\
\hline
\end{tabular}
avalanche safety operations 
Jamieson, 2009) using sky cover and precipitation data along with the latitude, aspect and slope incline of each start zone. The model has an estimated RMSE of $1.6^{\circ} \mathrm{C}$.

Each parameter was first analyzed for the 38 avalanches of known primary cause-of-release to group the avalanches of unknown primary cause-of-release. To identify the most significant parameters, each parameter was computed for the known primary cause-of-release subgroups and compared with each other using the Kruskal-Wallis one-way analysis of variance test (Kruskal and Wallis, 1952). This nonparametric test measures if two or more independent samples are from the same distribution. Distributions of parameters were significantly different from each other for $p<0.05$. The parameters were also assessed by comparing the prominent primary cause-of-release group of that parameter with the remainder of the subset data. For example, for the precipitation parameters, the precipitation loading group was compared with the combination of the other three primary causes-of-release groups. This comparison was completed using the Mann-Whitney $U$ test (Wilcoxon, 1945; Mann and Whitney, 1947), which is a nonparametric test that measures if one distribution is stochastically greater than another.

Once the most significant parameters were identified, they were used to create a multivariate classification tree (Breiman and others, 1984). For each case in a dataset, a classification tree uses one or more predictor variables to predict the class of the categorical response variable to which each case belongs. Classification trees are nonparametric and do not rely on the distributions of the variables. Trees have been created to identify important parameters and threshold values for avalanche forecasters. The trees are often pruned using the lowest cross-validated error to reduce the probability of misclassification. In our case, a minimum split of four cases was applied to provide enough detail to separate all four groups. This method will over-fit the data, but it was deemed acceptable so the tree could be used to group each of the remaining 139 avalanches into one of the four groups.

With all avalanches classified by their primary cause-ofrelease, the weather parameters were separated by avalanche days and non-avalanche days. For this study, avalanche days were classified as days that deep slab avalanches released along with the preceding $7 \mathrm{~d}$. Days 8-14 before each avalanche were classified as non-avalanche days. Such days did not release difficult-to-forecast deep slab avalanches, and buried persistent weak layers were present in the snowpack during those days. The parameters for each group were compared with the parameters calculated for the nonavalanche days using the Mann-Whitney $U$ test. Another group was created for comparison of weather parameters, called average winter climate, which included the entirety of the reported weather from all operations between the months November and April. Summary statistics were calculated for all the groups.

\section{RESULTS}

\subsection{Avalanche characteristics}

The InfoEx dataset contained some information about the observed avalanches, with particular reference to the start zone and slab characteristics. The observers often provided approximate data and some data were not available for certain avalanches when the start zones could not be adequately observed. Within the dataset, many of the start zones $(43 \%)$ were on northerly aspects. The start zone elevation was most often between 2000 and $2500 \mathrm{~m}$ (Table 2), consistent with the treeline and alpine terrain for much of western Canada. The median incline was $37^{\circ}$ with a range between $20^{\circ}$ and $50^{\circ}$. The median destructive size, described by the Canadian avalanche size (CAA, 2014), was 2.5 and varied between sizes 1 and 4 . The average slab thickness was $1 \mathrm{~m}$, ranging between 0.2 and $3.5 \mathrm{~m}$. Width of the slabs varied between 20 and $2000 \mathrm{~m}$ with a median of $150 \mathrm{~m}$. The avalanche length ranged from 20 to $2500 \mathrm{~m}$ with $83 \%$ of the data $<1000 \mathrm{~m}$. All of the avalanches occurred between the months of November and April. Most of the avalanches were reported in March (53\%), followed by January (28\%). The persistent weak layers ranged from 16 to $115 \mathrm{~d}$ old with a median of $36 \mathrm{~d}$. The majority of the persistent weak layers (76\%) released between 20 and $50 \mathrm{~d}$ after burial.

\subsection{Classification tree of known primary cause-of-release}

The multivariate classification tree based on avalanches with known primary cause-of-release and used to classify the remainder of the avalanches with unknown primary cause-ofrelease is presented in Figure 2. The primary split was the SWarm value. This parameter was used two more times lower in the tree, to group the data in conjunction with air temperature, wind loading and precipitation thresholds. This tree correctly classified 33 of the 38 avalanches (87\%) with reported known primary cause-of-release. Of the five incorrectly classified avalanches, one was from the precipitation loading group, two were from the wind loading group, one was from the solar warming group and one was from the air temperature warming group (Table 3 ).

\subsection{Weather parameters}

\subsubsection{Precipitation parameters}

Differences in precipitation parameter values were observed between each primary cause-of-release group (Table 4). The $24 \mathrm{~h}$ precipitation amounts were low for the solar and air temperature warming with median values of $0 \mathrm{~cm}$ of snowfall (Fig. 3). The wind loading group, non-avalanche days and average winter climate groups all had median $24 \mathrm{~h}$ snowfall values between 1 and $3 \mathrm{~cm}$ of snow. The precipitation group had the highest median value of $15 \mathrm{~cm}$ of snowfall. Also for the 3 and $7 \mathrm{~d}$ cumulative precipitation, the precipitation group had the highest median amounts (Table 4). When comparing the precipitation amounts for each group against the non-avalanche days, a significant difference was found for all of the distributions of cumulative amounts for both the air warming and precipitation groups (all $p<0.01$ ). The $24 \mathrm{~h}$ precipitation and the $3 \mathrm{~d}$ cumulative precipitation distributions were also significantly lower for the solar warming group compared with the non-avalanche days $(p<0.01$ and $p=0.04$, respectively).

The maximum precipitation rate on the days of release was highest for the precipitation group. The wind loading group and non-avalanche days were the only other groups that had a median maximum precipitation rate $>0 \mathrm{~cm} \mathrm{~h}^{-1}$, but the 75th percentile for those groups were lower than for the precipitation group. The distributions of the precipitation loading, wind loading and solar warming primary cause- 


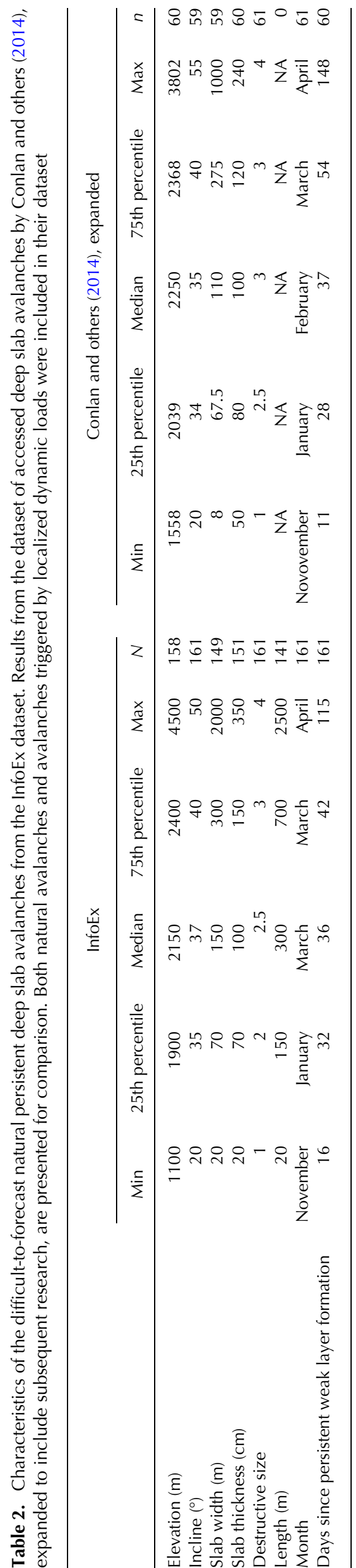

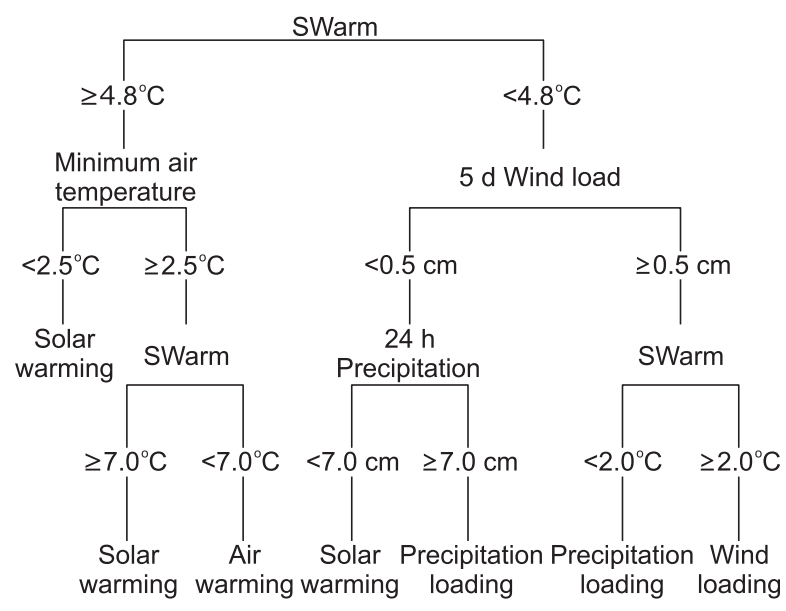

Fig. 2. Multivariate classification tree for deep slab avalanches of known primary cause-of-release. A minimum split of four was applied in combination with the lowest cross-validated error so all cases were classified. Minimum temperature, SWarm and $24 \mathrm{~h}$ precipitation are for the days of avalanche release.

of-release groups were significantly different than the distribution of the non-avalanche days with respect to the maximum precipitation rate (all $p<0.01$ ).

\subsubsection{Wind parameters}

Wind loading potential was low for all primary cause-ofrelease groups except for the wind loading group (Table 4); the median $24 \mathrm{~h}$ wind loading potential was $0 \mathrm{~cm}$ of snow for all groups except the wind loading group. Furthermore, the median $7 \mathrm{~d}$ cumulative wind loading potential was below $1 \mathrm{~cm}$ of snow for all groups except the wind loading group. Significant differences were observed between the distribution of the wind loading group and the distribution of the non-avalanche days for the cumulative wind loading potential parameters (all $p<0.01$ ). Wind loading potential was calculated using a specific aspect (Eqn (2)) and hence could not be calculated for the average winter climate. Maximum observed wind speed on the days of release was generally low. The wind loading potential group had the highest median wind speed of $33 \mathrm{~km} \mathrm{~h}^{-1}$. The group with the second highest median wind speed was the precipitation group. Both of these groups had distributions that were significantly different than the distribution of the non-avalanche days (both $p<0.01$ ).

\subsubsection{Solar warming parameters}

We analyzed sky cover as well as SWarm because only sky cover could be analyzed for the average winter climate, since aspects and slope angles were not available for this group. Sky cover on the days of avalanche releases was generally less for the solar warming group compared with all the other groups (Table 4). The highest median sky cover was observed for the precipitation, wind loading and average winter climate groups. Similarly, the highest median SWarm value on the days of release was observed for the solar warming group and the lowest being for the precipitation group (Fig. 4), largely because of SWarm's dependence on sky cover. The median $1 \mathrm{~d}$ change of SWarm values between the day of the release and the day before the release was greatest for the solar warming group followed by the air warming group, with the remainder of the groups 
Table 3. Evaluated and modelled grouping of avalanches with known primary cause-of-release. The evaluated primary cause-of-releases were determined from avalanche professionals, whereas the modelled amounts were determined from the multivariate classification tree

Evaluated primary cause-of-release

\begin{tabular}{|c|c|c|c|c|}
\hline & \\
\hline & Precipitation loading & Wind loading & Solar warming & Air temperature warming \\
\hline \multicolumn{5}{|c|}{ Modelled primary cause-of-release } \\
\hline Precipitation loading & 10 & 1 & 1 & - \\
\hline Wind loading & 1 & 7 & - & - \\
\hline Solar warming & - & 1 & 15 & 1 \\
\hline Air temperature warming & - & - & - & 1 \\
\hline
\end{tabular}

having no change for the median value (Table 4). All solar warming parameters were significantly different for the distribution of the solar warming group compared with the distribution of the non-avalanche days (all $p<0.01$ ). SWarm was also significantly different for the distribution of the air warming and precipitation groups compared with the distribution of the non-avalanche days (both $p<0.01$ ).

\subsubsection{Air temperature warming parameters}

Both the daily maximum and daily minimum air temperature medians were highest for the air warming group compared with the other groups (Table 4). The next warmest median maximum air temperature was for the solar warming group, although that group's median minimum air temperature was the lowest of all groups. The precipitation group had the next highest median minimum air temperature. For the $1 \mathrm{~d}$ change between the air temperature on the day of release and on the day before the release, the highest median value for maximum daily temperature change occurred within the air warming and the precipitation groups. A high value also occurred in the precipitation group for the minimum air temperature change, whereas a negative (minor cooling) median value of $-0.7^{\circ} \mathrm{C}$ occurred for the air temperature warming group. No air temperature change was found in the median value of the solar warming, nonavalanche days and the average winter climate groups. The daily maximum air temperature, the daily minimum air temperature and the maximum $1 \mathrm{~d}$ temperature change were all significantly different between the distribution of the air warming group and the distribution of the non-avalanche days ( $p<0.01, p<0.01, p=0.05$, respectively).

\section{DISCUSSION}

\subsection{Avalanche characteristics}

The persistent deep slab avalanches within the InfoEx dataset had characteristics comparable with those presented by Conlan and others (2014), which included both natural and artificial releases. The results in Conlan and others (2014) included difficult-to-forecast persistent deep slab avalanches up to 2012. Avalanches in 2013 and 2014 were added to their results and compared with the InfoEx dataset in our study to identify if our InfoEx dataset was representative of other observed persistent deep slab avalanches in western Canada. Most of the parameters had similar distributions for the two datasets (Table 2).

Close to half of the avalanches were on northerly aspects in the InfoEx dataset (Table 2). This is likely because persistent weak layers are often further formed and better preserved on north aspects with higher temperature gradients favoring layers of faceted crystals and surface hoar. Furthermore, the predominant southwesterly winds in western Canada produce greater loads from snowfall and wind-transported snow on northerly aspects. The start zone elevations indicate that most avalanches in our dataset occurred at or above the treeline in western Canada. Most deep slab avalanches occur in such terrain likely because of the higher possibility of spatial continuity of persistent weak layers with no vegetation or sparse trees. Deep slab avalanches that occur below the treeline generally occur in areas cleared of trees, such as in gullies and cut blocks from logging. For incline, deep slab avalanches tend to occur more often on shallower terrain compared with other avalanches as steeper slopes often release when the failure layers and interfaces are younger.

Of interest is the lack of destructive size 5 avalanches in both datasets. It is possible that there were none because of the potential underestimation of avalanche size (Jamieson and others, 2014). Destructive size generally correlates with slab thickness, with thinner slabs often producing lower destructive size avalanches. The InfoEx dataset had one difficult-to-forecast slab avalanche with a surprisingly low reported slab thickness of $20 \mathrm{~cm}$ and a few near $50 \mathrm{~cm}$. It is possible that these were input errors or the thicknesses were underestimated. The avalanche characteristics were often observed from a distance and estimated in this dataset. Avalanche professionals may underestimate slab characteristics when they are observed from afar (Jamieson and others, 2014). The large variability observed with slab width may be partly due to estimation errors but is more likely because of the terrain and start zone characteristics. Avalanche lengths were available for the InfoEx dataset and like widths, they varied substantially. Lengths are also dependent on terrain and the path characteristics, consequently yielding large variations.

For both datasets, most avalanches occurred in March with a second peak in January. For the InfoEx dataset, this grouping may reflect the reporting period from the contributing organizations, many of which only operate between December and March, and the peak season for many of the backcountry operations is February and March. This reporting effect is likely why early and late-season deep slab avalanches were under-represented. However, a peak of deep slab avalanches in mid-winter has also been observed by others, including the months of December and January (Bradley, 1970; Comey and McCollister, 2008; Tracz, 2012) and April (Bradley, 1970; Tracz, 2012). In western Canada, persistent weak layers are often produced in early February during periods of high pressure (Haegeli and McClung, 2007) as well as in October and November as a 
result of strong temperature gradients in the snowpack. Such weak layers are buried and produce large avalanche cycles in the weeks following weak layer creation and subsequent persistent deep slab avalanches in the following months (i.e. December, January, March and April).

The commonalities in the two datasets suggest that this InfoEx dataset is representative of naturally triggered persistent deep slab avalanches in western Canada. We therefore expect that the trends observed from the avalanche characteristics as well as the weather parameters are representative of what may be found during any given winter.

\subsection{Classification tree for primary cause-of-release}

SWarm was used as the primary split and in two subsequent splits to classify the cause of release. It is a prominent parameter, likely because it depends on both sky cover and precipitation. Days that had avalanche release from solar warming logically will experience high calculated SWarm values due to clear skies and sunny aspects. Days on which avalanches release from precipitation loading will generally experience low SWarm values because of overcast or obscured skies and high surface albedo. Thus, the primary split in the classification tree separated the days that released from increased strain rates from temperature warming from those that released from snow loading. The remainder of the splits generally used weather parameters related to the groups that the parameters separated. Some of the splits lower in the tree are not as intuitive. For example, SWarm may not seem to be a logical parameter to separate the precipitation group from the wind loading group, but low values are expected to be associated with the precipitation group, whereas somewhat higher values may be associated with the wind loading group, which does not require overcast or obscured sky conditions. However, physical explanations are not obvious for some splits, such as low wind loading and high precipitation amounts separating the precipitation loading group. This could partly be explained by storms without associated wind, or by start zone and wind direction angles that do not promote wind loading.

The classification tree had an accuracy of $87 \%$ for the avalanches that were used to build the tree, similar to those found in other avalanche forecasting studies (e.g. Hendrikx and others, 2005; Hendrikx and others, 2014). Although this tree classifies cause of release rather than predicting avalanche days, the accuracy suggests the classification tree may be valuable for avalanche forecasters in western Canada to determine the primary release mechanisms, both spatially and temporally, for their forecasting area. Also, classifying such avalanches could help avalanche forecasters determine thresholds for weather parameters, as another forecasting aid.

\subsection{Primary causes-of-release groups}

\subsubsection{Precipitation loading}

High precipitation amounts and precipitation rates on the day of avalanches that likely released from snowfall are expected. The median $24 \mathrm{~h}$ snowfall of $15 \mathrm{~cm}$ was lower than found in other studies; however, most of the weather stations for the precipitation data were at or below the treeline, which typically experiences less precipitation than in the alpine where many of the avalanches started. A scale factor is required to estimate the increased load in alpine start zones. Using the scale factor from the MicroMet model by Liston and Elder (2006), a $24 \mathrm{~h}$ snowfall of $15 \mathrm{~cm}$ at $1800 \mathrm{~m}$ would be between 20 and $30 \mathrm{~cm}$ for an elevation of $2200-2750 \mathrm{~m}$. This will increase the $3 \mathrm{~d}$ precipitation amounts from a median of $38 \mathrm{~cm}$ to a median of $\sim 50-80 \mathrm{~cm}$ using the same typical alpine start zone elevations of western Canada, comparable with the findings of Schneebeli and others (1997) in Switzerland. Avalanche forecasters in western Canada can likely use the $24 \mathrm{~h}$ values of $15 \mathrm{~cm}$ of snow at their manual weather stations or $20-30 \mathrm{~cm}$ in alpine terrain as a threshold amount that may naturally trigger persistent deep slab avalanches.

There are of course many days with such snowfall amounts that do not release persistent deep slab avalanches. This is because precipitation is not the only factor for such avalanches. A persistent weak layer must be present in the snowpack, potentially with stiffer layers above or below, which will concentrate stress at the upper or lower interface. Other weather parameters may also be required for some of the releases to occur. For example, relatively warm air is often associated with storms in western Canada (Stewart and others, 1995). The warm air may aid in the release of deep slabs by increasing the creep rate in the upper snow, which may critically strain buried persistent weak layers. The combination of lower amounts of precipitation loading and warming may be required to release avalanches in certain start zones. Air temperature warming was observed for many of the avalanches with precipitation loading as the primary cause-of-release (Table 4), likely because of the association with storms.

The highest median sky cover and the lowest median SWarm value on the days of release occurred in the precipitation loading group because of cloud cover associated with storms. The distributions of the sky cover for the precipitation loading group and the non-avalanche days were similar but still significantly different (Table 4). They were also close to the average winter climate. This indicates that much of the winter season in western Canada is cloudy, consistent with the low pressure systems stemming from the Aleutian Low over the Gulf of Alaska (Klock and Mullock, 2001). The strong low pressure systems with associated snowfall are those that are likely to cause the release of the persistent deep slab avalanches in this group.

\subsubsection{Wind loading}

The potential wind loading amounts for all groups were lower than anticipated. Wind speeds were consistently low, likely because the weather stations were mostly at or below the treeline and in sheltered areas. Many observations indicated calm winds, which resulted in calculated wind loading of zero. Also, wind was usually observed at the weather stations early in the morning when winds are generally weaker than at mid-afternoon. It is probable that the wind speeds observed at the weather stations were not representative of the start zones because of these factors and that wind loading was underestimated in this analysis. Avalanche forecasters should therefore not use the median values found in our study. The wind loading potential calculation, however, holds promise if representative wind speeds and directions are available. The amount of wind-transported snow required to release a deep slab avalanche is likely similar to the amounts observed with precipitation loading.

The highest $24 \mathrm{~h}$ wind loading potential of $60 \mathrm{~cm}$ that released an alpine deep slab avalanche was calculated for 
Table 4. Summary statistics of all difficult-to-forecast natural persistent deep slab avalanches

\begin{tabular}{|c|c|c|c|c|c|c|c|c|c|c|c|c|c|c|c|c|}
\hline \multirow[t]{3}{*}{ Group } & \multirow[t]{3}{*}{ Statistic } & \multicolumn{4}{|c|}{ Precipitation parameters } & \multicolumn{4}{|c|}{ Wind parameters } & \multicolumn{3}{|c|}{ Solar warming parameters } & \multicolumn{4}{|c|}{ Air temperature parameters } \\
\hline & & $\begin{array}{l}24 \mathrm{~h} \\
\text { precipitation }\end{array}$ & $\begin{array}{l}3 \mathrm{~d} \\
\text { precipitation }\end{array}$ & $\begin{array}{l}7 \mathrm{~d} \\
\text { precipitation }\end{array}$ & $\begin{array}{l}\text { Max } \\
\text { precipitation } \\
\text { rate }\end{array}$ & $\begin{array}{l}24 \mathrm{~h} \\
\text { wind } \\
\text { load }\end{array}$ & $\begin{array}{l}3 \mathrm{~d} \\
\text { wind } \\
\text { load }\end{array}$ & $\begin{array}{l}7 \mathrm{~d} \\
\text { wind } \\
\text { load }\end{array}$ & $\begin{array}{l}\text { Max } \\
\text { wind } \\
\text { speed }\end{array}$ & $\begin{array}{l}\text { Sky } \\
\text { cover }\end{array}$ & SWarm & $\begin{array}{l}1 \mathrm{~d} \\
\text { SWarm } \\
\text { change }\end{array}$ & $\begin{array}{l}\text { Max } \\
\text { temperature }\end{array}$ & $\begin{array}{l}\text { Min } \\
\text { temperature }\end{array}$ & $\begin{array}{l}1 \mathrm{~d} \text { max } \\
\text { temperature } \\
\text { change }\end{array}$ & $\begin{array}{l}1 \mathrm{~d} \text { min } \\
\text { temperature } \\
\text { change }\end{array}$ \\
\hline & & cm snow & cm snow & cm snow & $\mathrm{cm} \mathrm{h}^{-1}$ & $\begin{array}{l}\mathrm{cm} \\
\text { snow }\end{array}$ & $\begin{array}{l}\mathrm{cm} \\
\text { snow }\end{array}$ & $\begin{array}{l}\mathrm{cm} \\
\text { snow }\end{array}$ & $\begin{array}{l}\mathrm{km} \\
\mathrm{h}^{-1}\end{array}$ & & $\begin{array}{l}{ }^{\circ} \mathrm{C} 10 \\
\mathrm{~cm} \\
\text { into } \\
\text { snow }\end{array}$ & $\begin{array}{l}{ }^{\circ} \mathrm{C} 10 \\
\mathrm{~cm} \text { into } \\
\text { snow }\end{array}$ & ${ }^{\circ} \mathrm{C}$ & ${ }^{\circ} \mathrm{C}$ & ${ }^{\circ} \mathrm{C}$ & ${ }^{\circ} \mathrm{C}$ \\
\hline \multirow{6}{*}{$\begin{array}{l}\text { Precipitation } \\
\text { loading }\end{array}$} & $n$ & 62 & 60 & 52 & 60 & 61 & 57 & 48 & 62 & 62 & 62 & 61 & 62 & 62 & 61 & 61 \\
\hline & Minimum & 2 & 3 & 16 & 0.0 & -16.1 & -37.8 & -55.7 & $\mathbf{0}$ & CLR & 1.1 & -2.1 & -11 & -21 & -10 & -10 \\
\hline & $\begin{array}{l}\text { 25th per- } \\
\text { centile }\end{array}$ & 8 & 24 & 41 & 0.5 & -0.1 & -0.1 & -0.6 & $\mathbf{0}$ & BKN & 1.4 & 0.0 & -4 & -9 & -1 & -1 \\
\hline & Median & 15 & 38 & 68 & 0.5 & 0.0 & 0.0 & 0.0 & 13 & OBS & 2.3 & 0.0 & -2 & -6 & 1 & 1 \\
\hline & $\begin{array}{l}\text { 75th per- } \\
\text { centile }\end{array}$ & 22 & 61 & 96 & 2.0 & 0.1 & 0.3 & 0.7 & 29 & OBS & 3.2 & 0.0 & 0 & -4 & 2 & 3 \\
\hline & Maximum & 63 & 125 & 152 & 4.0 & 5.1 & 17.7 & 28.8 & 75 & $\mathbf{X}$ & 4.7 & 1.8 & 6 & $\mathbf{0}$ & 7 & 7 \\
\hline \multirow{6}{*}{$\begin{array}{l}\text { Wind } \\
\text { loading }\end{array}$} & $n$ & 21 & 19 & 17 & 20 & 21 & 19 & 15 & 21 & 21 & 21 & 21 & 21 & 21 & 21 & 21 \\
\hline & Minimum & 0 & 0 & 5 & 0.0 & 0.0 & 0.0 & 0.7 & $\mathbf{0}$ & CLR & 1.3 & -4.2 & -11 & -17 & -4 & -5 \\
\hline & $\begin{array}{l}\text { 25th per- } \\
\text { centile }\end{array}$ & 1 & 2 & 26 & 0.0 & 0.3 & 0.7 & 6.1 & 19 & BKN & 2.7 & 0.0 & -6 & -11 & -2 & -2 \\
\hline & Median & 3 & 15 & 45 & 0.5 & 6.0 & 6.9 & 13.6 & 33 & OBS & 3.2 & 0.0 & -2 & -7 & 0 & 1 \\
\hline & $\begin{array}{l}\text { 75th per- } \\
\text { centile }\end{array}$ & 12 & 28 & 49 & 1.3 & 10.5 & 24.7 & 53.4 & 51 & OBS & 3.5 & 0.5 & 0 & -5 & 3 & 3 \\
\hline & Maximum & 22 & 61 & 85 & 4.0 & 59.7 & 118.3 & 210.3 & 100 & $x$ & 4.2 & 1.9 & 10 & 5 & 9 & 13 \\
\hline \multirow{6}{*}{$\begin{array}{l}\text { Solar } \\
\text { warming }\end{array}$} & $n$ & 74 & 72 & 65 & 72 & 74 & 66 & 57 & 74 & 74 & 74 & 73 & 74 & 74 & 73 & 73 \\
\hline & Minimum & 0 & $\mathbf{0}$ & 0 & 0.0 & -0.3 & -4.9 & -16.1 & 0 & CLR & 0.6 & -6.3 & -16 & -22 & -13 & -11 \\
\hline & $\begin{array}{l}\text { 25th per- } \\
\text { centile }\end{array}$ & $\mathbf{0}$ & 1 & 13 & 0.0 & 0.0 & 0.0 & -0.2 & 0 & CLR & 3.6 & 0.0 & -5 & -12 & -2 & -3 \\
\hline & Median & $\mathbf{0}$ & 6 & 24 & 0.0 & 0.0 & 0.0 & 0.0 & 11 & FEW & 5.2 & 0.7 & o & -9 & 0 & $\mathbf{0}$ \\
\hline & $\begin{array}{l}\text { 75th per- } \\
\text { centile }\end{array}$ & 1 & 14 & 40 & 0.0 & 0.1 & 0.2 & 0.2 & 13 & BKN & 7.0 & 1.5 & 3 & -6 & 2 & 1 \\
\hline & Maximum & 15 & 66 & 104 & 0.5 & 4.8 & 7.7 & 17.6 & 39 & $\mathbf{X}$ & 16.9 & 9.2 & 11 & 1 & 7 & 9 \\
\hline \multirow[t]{6}{*}{ Air warming } & $n$ & 19 & 18 & 15 & 16 & 19 & 18 & 13 & 19 & 19 & 19 & 18 & 19 & 19 & 18 & 18 \\
\hline & Minimum & $\mathbf{0}$ & 0 & $\mathbf{0}$ & 0.0 & 0.0 & 0.0 & -10.1 & 0 & CLR & 1.2 & -2.3 & -3 & -13 & -1 & -8 \\
\hline & $\begin{array}{l}\text { 25th per- } \\
\text { centile }\end{array}$ & $\mathbf{0}$ & $\mathbf{0}$ & 4 & 0.0 & 0.0 & 0.0 & 0.0 & 0 & SCT & 3.0 & 0.0 & 2 & -3 & 0 & -2 \\
\hline & Median & $\mathbf{0}$ & 2 & 14 & 0.0 & 0.0 & 0.0 & 0.4 & 0 & BKN & 4.3 & 0.3 & 5 & -1 & 1 & -1 \\
\hline & $\begin{array}{l}\text { 75th per- } \\
\text { centile }\end{array}$ & $\mathbf{0}$ & 16 & 26 & 0.0 & 0.1 & 0.5 & 1.8 & 13 & OBS & 5.2 & 0.9 & 7 & $\mathbf{0}$ & 2 & 1 \\
\hline & Maximum & $\mathbf{0}$ & 30 & 89 & 0.5 & 1.8 & 8.9 & 3.2 & 33 & $X$ & 6.5 & 2.5 & 10 & 2 & 5 & 7 \\
\hline
\end{tabular}




$$
\begin{aligned}
& \text { 는? } \\
& \text { ूํำ }
\end{aligned}
$$

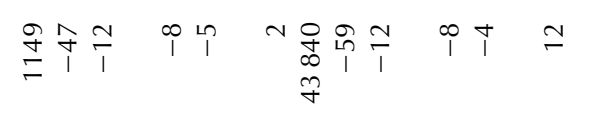

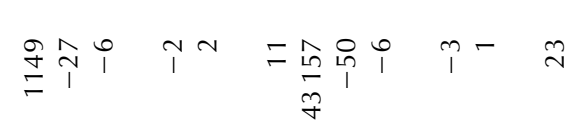

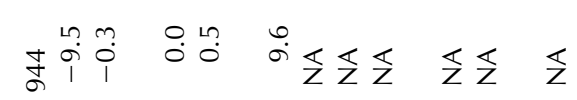

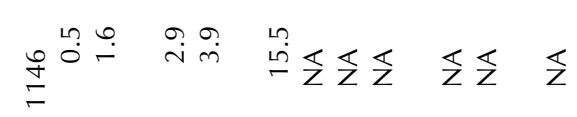

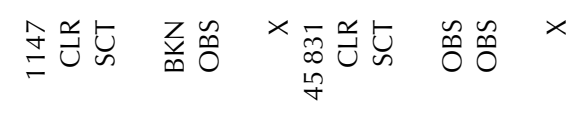

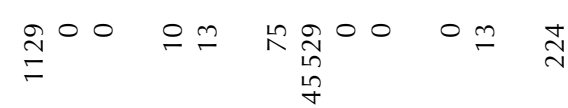

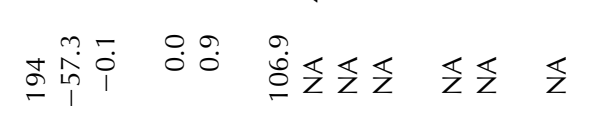

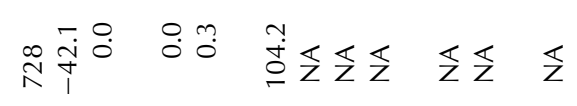

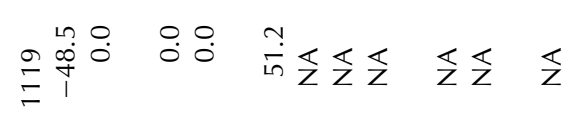

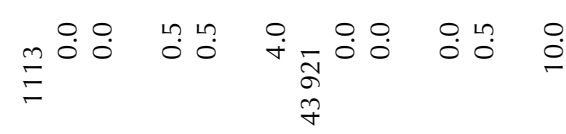

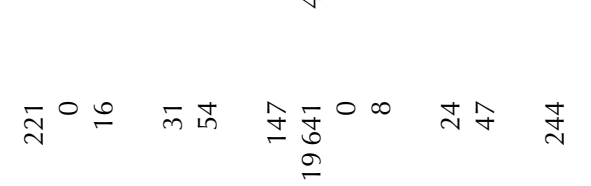

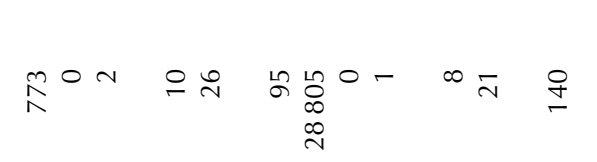

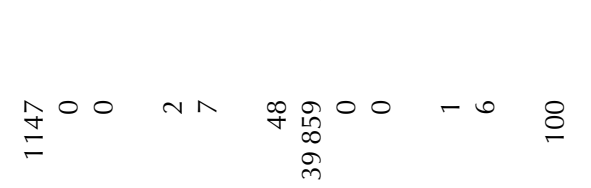

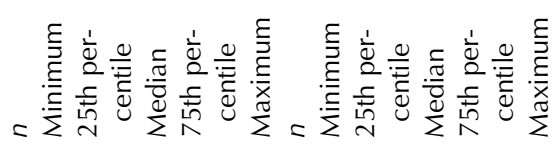

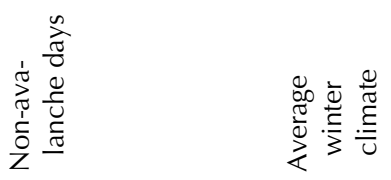

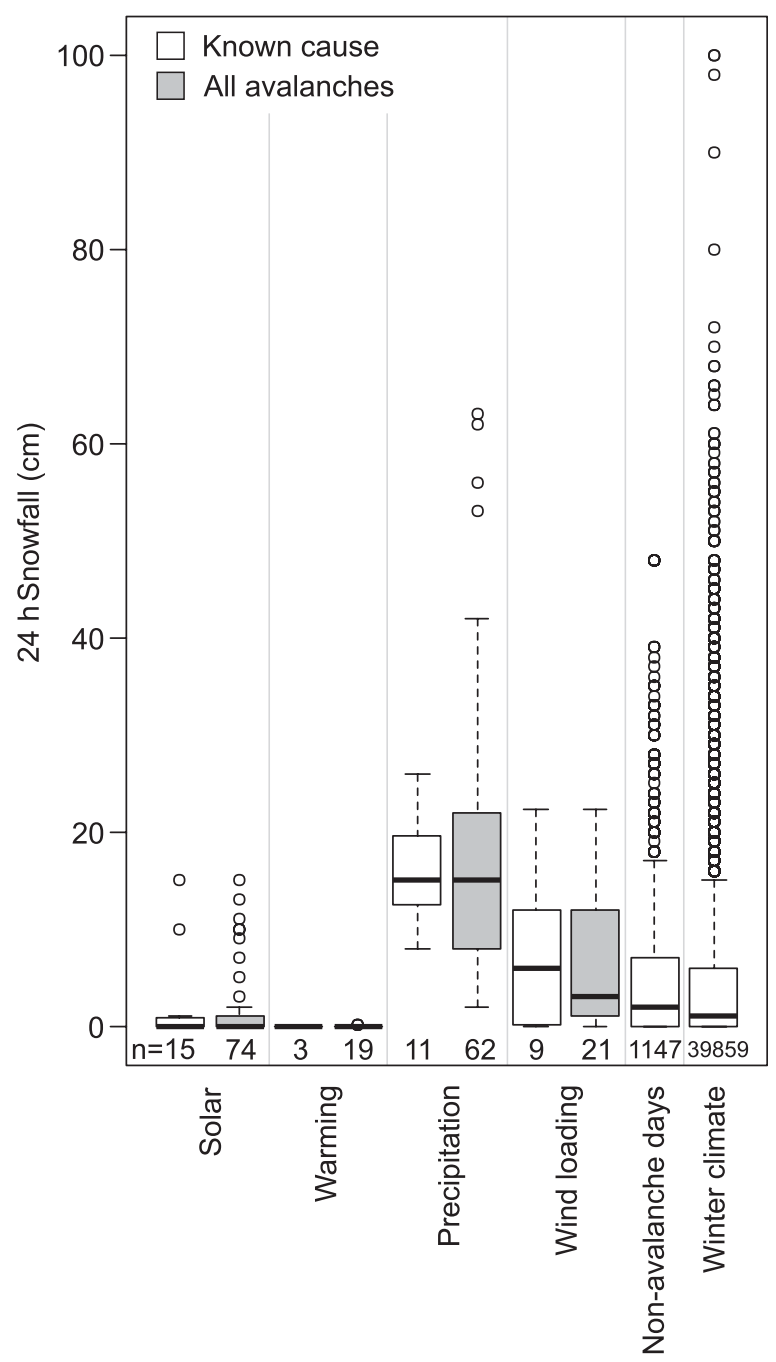

Fig. 3. Boxplots of $24 \mathrm{~h}$ snowfall on the days of avalanche releases for each respective primary cause-of-release, non-avalanches days and average winter climate. Both the known primary cause-ofrelease groups and the entire classified dataset groups are displayed. Number of observations $(n)$ for each group is reported below each boxplot. The black line indicates the median, boxes span the first and third quartiles, whiskers span the lowest datum and the highest datum within 1.5 times the lower and upper quartiles, respectively, and outliers are displayed as open circles.

an operation that had an alpine weather station. These maximum wind speeds were much larger than most other observations because of the elevation of the stations. Although expensive and sometimes impractical, wind data from an alpine weather station provide useful information to practitioners that forecast for alpine terrain (CAA, 2014).

Although most wind loading potential amounts were less than expected, the median wind speeds and wind loading potential were higher for the wind loading group than all other groups (Table 4). Many of the avalanches also had some recorded snowfall because precipitation events are often associated with moderate to strong winds during storms. This explanation is also consistent with most of the avalanches having some cloud cover. This group having the second highest maximum air temperature on the day of the release may also be because of the association with storms (Stewart and others, 1995). 


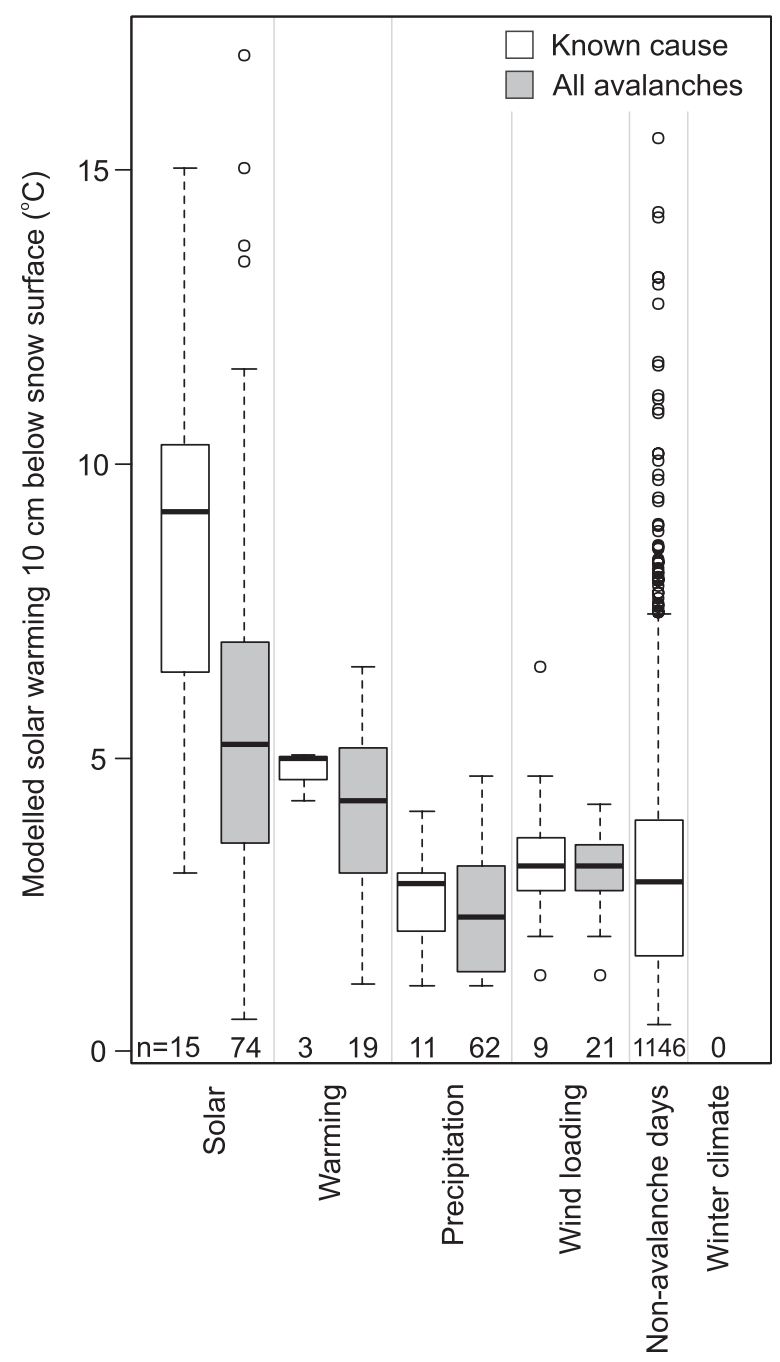

Fig. 4. Boxplots of modelled solar warming from the model SWarm on the days of avalanche releases for each respective primary causeof-release, non-avalanches days and average winter climate. Both the known primary cause-of-release groups and the entire classified dataset groups are displayed. Number of observations $(n)$ for each group is reported below each boxplot. Boxplot format is the same as Figure 3.

\subsubsection{Solar warming}

Some avalanche forecasters are less concerned about the influence of solar warming during winter months than in the spring (e.g. Conlan and Jamieson, 2014). However, our study suggests that many avalanches likely release from solar warming in winter months, indicating the importance of monitoring incoming shortwave radiation along with other weather parameters. This is often difficult for operations in western Canada because upward-facing pyranometers must be ventilated to remain clear of falling snow. The simple model SWarm offers useful guidance as to potential near-surface warming from incoming shortwave radiation.

Low sky cover and high SWarm values are expected for avalanches that release because of solar warming, which was generally observed in the solar warming group. Exner and Jamieson (2008) indicate that a large storm often occurs prior to the release of slab avalanches that are solar induced. This dataset indicates that some new snow often fell in the preceding days but that some deep slab releases occur after prolonged days of solar warming. For such days, settling and perhaps melting may occur with the prolonged warming that may allow buried persistent weak layers to be closer to the surface and more influenced by the increased strain rates from intense solar warming. Furthermore, prolonged days of clear skies lowers surface albedo, thereby increasing warming of the upper snowpack and potentially favouring avalanche release.

When comparing the modelled solar warming distributions of the known primary cause-of-release groups with the entire classified data, some differences were observed (Fig. 4). The solar warming group had many lower SWarm values because of the splits of the classification tree. It included many avalanches with high SWarm values but also some with low values. Because of this, the distribution of the known primary cause-of-release group is probably more representative even though the dataset was smaller. However, the median value of $5.2^{\circ} \mathrm{C}, 10 \mathrm{~cm}$ into the snowpack is still likely a reasonable threshold for forecasting, as this value includes most of the avalanches for which the known primary cause-of-release was solar warming.

The solar warming group had the second highest median maximum air temperature on the days of release but the lowest median minimum air temperature on the days of release. This is likely partly related to the high diurnal trends that often occur with high pressure systems and associated clear skies in winter months. Daytime warming occurs from incoming shortwave radiation, whereas rapid surface cooling occurs at night with increased outgoing longwave radiation under cloudless skies. A combination of warm daytime air temperatures and low to moderate incoming shortwave radiation amounts may trigger some persistent deep slab avalanches, where incoming shortwave radiation by itself is not enough to cause critical strain rates in the snowpack.

Two days in the dataset had $24 \mathrm{~h}$ snowfall amounts of $10-15 \mathrm{~cm}$ but were deemed by avalanche professionals to have released because of solar warming (Fig. 3). Comments associated with these releases indicated that the snowfall occurred overnight and in the early mornings, followed by clearing and intense incoming shortwave radiation during the day. SWarm values for these days reached between 5 and $10^{\circ} \mathrm{C}$ of warming, $10 \mathrm{~cm}$ into the snowpack. These examples highlight the difficulties of analyzing daily observations for avalanche forecasting. Hourly data provide more insight into intense periods of a respective weather parameter. However, many of the backcountry operations do not have the ability to obtain automatically recorded hourly data and are limited to daily or twice per day observations at manual weather stations plus roving field weather observations. Further, a limitation of SWarm is that it is a daily model. Other measurements such as incoming shortwave radiation from a pyranometer may be useful.

\subsubsection{Air temperature warming}

Most of the avalanches in the air temperature warming group exhibited maximum air temperatures near or above $0^{\circ} \mathrm{C}$ on the days of release (Table 4), which is expected. Maximum temperatures within many of the start zones were likely a few degrees cooler because most avalanches released at higher elevations than at the weather stations, although some may have been warmer if inversion conditions occurred. Little to no snowfall is also expected for these avalanches, as shown in Table 4.

There were only a few avalanches for which the primary cause-of-release was air temperature warming, likely 
because air temperature rarely reaches above freezing temperatures at the treeline and alpine terrain in winter. Such air temperatures generally occur in the spring. Since many of the reporting operations shut down in April, avalanches that release because of warm air temperatures were likely under-reported in the InfoEx dataset.

\subsubsection{Other primary causes-of-release}

The four primary causes-of-release described in our study are the most prominent causes of natural releases during winter and early spring months in mountainous terrain of western Canada but other methods can trigger the initial fracture in a persistent weak layer. One method often discussed by avalanche professionals is rapid cooling of the snowpack. Speculative release mechanisms for rapid cooling are discussed by Floyer (2012). None of the persistent deep slab avalanches in this dataset were thought to have released because of cooling. Hourly or finer data in the study area would likely be required to analyze releases due to this mechanism.

Rain is another primary cause-of-release that more often occurs in late spring but can happen in the middle of winter, particularly at lower elevations. In such situations, free water can flow through the pore spaces of the snowpack and influence the mechanical properties of buried persistent weak layers. This release mechanism was not applicable to this dataset because it would have been listed as a wet avalanche. On a few occasions, light rain was listed in the precipitation rate on the days of release at the weather station. In most circumstances the rain occurred at lower elevations but snow was the predominant precipitation type at higher elevations where most of the avalanches released. Rain events are also typically short during winter months and rarely long enough to wet surficial snow layers, thereby adding load similar to snowfall for deeply buried weak layers. Conway and Raymond (1993) indicate that only a small amount of rain ranging from minutes to an hour is required to trigger slab avalanches. However, the slabs in their study were generally $30-50 \mathrm{~cm}$ in depth and such thin slabs would only occur locally for deep slab avalanches with highly variable slab thicknesses.

Localized dynamic loads can also trigger deep slab avalanches. This cause-of-release group includes loading by humans (e.g. skiers, snowmobilers), as well as other loads such as animals, cornice falls, helicopters and explosives. Weather may play a secondary role in triggering such avalanches. Added load from precipitation or wind-transported snow in combination with localized dynamic loads may critically stress or increase strain rates in the persistent weak layer. Warming from air temperature or solar warming may reduce slab stiffness and strain rates may become critical from this in combination with high strain rates from localized dynamic loads. Such causes of release are challenging to analyze because the influence of weather parameters is relatively weak (Conlan and Jamieson, 2013).

\subsubsection{Application}

In contrast to previous studies that relate weather to avalanche occurrence, we have identified thresholds of weather parameters specifically for difficult-to-forecast avalanches. These thresholds may prove directly applicable in operational forecasting in western Canada and perhaps elsewhere. Further, the thresholds of various weather parameters may be combined in a forecasting tool such as a decision aid. However, values above the thresholds may be observed on many days where deep slab avalanches do not release (i.e. high false alarm ratio). High false alarm ratios and rates were observed in other avalanche forecasting studies (e.g. Hendrikx and others, 2005, 2014; Schweizer and others, 2009; Tracz, 2012). High false alarm ratios may be acceptable for difficult-to-forecast avalanches because of the high cost associated with a non-forecasted event (e.g. Blattenberger and Fowles, 1995). High costs are expected for large and destructive persistent deep slab avalanches that reach infrastructure or affect humans.

\section{SUMMARY}

Observations of natural deep slab avalanches and associated weather data were obtained from avalanche forecasting operations in western Canada. Avalanche characteristics were first analyzed. The avalanches were classified into four groups based on the weather parameters that were associated with the likely primary cause-of-release: precipitation loading, wind loading, solar warming and air temperature warming. Using weather parameters, a classification tree correctly classified $87 \%$ of the days with known primary causeof-release that were used to build the tree. The resulting tree was then used to classify avalanches without known cause of release. Once all avalanches were classified, univariate analyses were conducted by comparing the cause-of-release groups with non-avalanche days and average winter climate values.

Each primary cause-of-release group had the highest median of each important parameter associated with them; the precipitation loading group had the highest median snowfall amounts, the wind loading group had the highest median wind loading potentials, the solar warming group had the highest median SWarm values and the air temperature warming group had the highest median air temperature values on the days of release. The distributions of each of these parameters for the mentioned groups were significantly different than the distributions of the non-avalanche days.

For the precipitation group, the median $24 \mathrm{~h}$ snowfall of $15 \mathrm{~cm}$ is likely low because many weather stations were at or below the treeline whereas many of the avalanches released above the treeline. With elevation corrections, a $24 \mathrm{~h}$ snowfall of $20-30 \mathrm{~cm}$ is more likely associated with persistent deep slab avalanche release.

Similarly for the wind loading group, calculated wind loading potential values in this analysis were too low. This bias is because the wind speeds at the weather stations were low compared with winds experienced at higher elevation. Critical wind loading amounts are probably within the same range as the snowfall amounts discussed.

The solar warming group had a median SWarm value of $5.2^{\circ} \mathrm{C}$. This model is a tool for avalanche forecasters to use, not only during the spring but also in the winter when solar-triggered deep slab avalanches also occur (e.g. Conlan and Jamieson, 2014). The median value is likely relevant for avalanches that released after a dry storm whereas higher SWarm values may be required if a snow storm did not occur in the previous day or two.

The air temperature warming group's median maximum air temperature on the days of release of $5^{\circ} \mathrm{C}$ is likely higher than what was experienced in the start zones because the weather stations were generally at lower 
elevation than the start zones. Temperatures near-freezing may be important to the release of persistent deep slab avalanches when other weather parameters are not prominent.

Values from the classification tree and summary statistics may be useful for avalanche professionals in western Canada who observe persistent deep slab avalanches in their forecast area. The values can be used to determine under which situations such avalanches are more common, although using the values as thresholds may produce many false alarms. The next step in our research, using the results of this study and the weather model results from Part II, is to create a decision support tool to aid avalanche professionals in forecasting the likelihood of observing persistent deep slab avalanches.

\section{ACKNOWLEDGEMENTS}

We thank the Canadian Avalanche Association and all subscribing members to the InfoEx for the data. We thank the Avalanche Control Service of Parks Canada at Rogers Pass, B.C. and Mike Wiegele Helicopter Skiing at Blue River, B.C. for research facilities and logistical help. We thank the Natural Sciences and Engineering Research Council of Canada, Parks Canada, HeliCat Canada, the Canadian Avalanche Association, Mike Wiegele Helicopter Skiing, Canada West Ski Areas Association, Backcountry Lodges of British Columbia Association, the Association of Canadian Mountain Guides, Teck Mining Company, Avalanche Canada, the Canadian Ski Guide Association, Backcountry Access, the B.C. Ministry of Transportation and Infrastructure Avalanche and Weather Programs, the Canadian Avalanche Foundation and TECTERRA for their support of ASARC. We also thank three anonymous reviewers who provided comments that improved the quality of this manuscript.

\section{REFERENCES}

Akitaya E (1967) Some experiments on the growth of depth hoar. In Physics of Snow and Ice, Proceedings of the International Conference on Low Temperature Science, vol. 1(II), 713-723

Atwater M (1954) Snow avalanches. Sci. Am., 190(1), 26-31 (doi: 10.1038/scientificamerican0154-26)

Bakermans L and Jamieson B (2009) SWarm: a simple regression model to estimate near-surface snowpack warming for backcountry avalanche forecasting. Cold Reg. Sci. Technol., 59(2-4), 133-142 (doi: 10.1016/j.coldregions.2009.06.003)

Blattenberger $G$ and Fowles R (1995) Road closure to mitigate avalanche danger: a case study for Little Cottonwood Canyon. Int. J. Forecast., 11, 159-174 (doi: 10.1016/0169-2070(94) 02008-d)

Bois P, Obled C and Good W (1975) Multivariate data analysis as a tool for day-by-day avalanche forecast. In Proceedings of the International Symposium on Snow Mechanics, Grindelwald, Switzerland, IAHS Publication 114, 391-403

Bradley CC (1970) The location and timing of deep slab avalanches. J. Glaciol., 9(56), 253-261

Breiman L, Friedman L, Stone CJ and Olshen RA (1984) Classification and regression trees. Chapman and Hall/CRC, New York, NY, 358 pp

Canadian Avalanche Association (CAA) (2014) Observation guidelines and recording standards for weather, snowpack, and avalanches. Canadian Avalanche Association, Revelstoke, BC, 94 pp

Comey B and McCollister C (2008) Deep slab instability characterizing the phenomena - part 1. In Proceedings of the 2008
International Snow Science Workshop, 21-27 September 2008, Whistler, BC, 315-321

Conlan M and Jamieson B (2014) Case study of a solar triggered persistent deep slab avalanche. Proceedings of Geohazards6, 15-18 June 2014, Kingston, ON, 6 pp

Conlan M and Jamieson B (2016) Naturally triggered persistent deep slab avalanches in western Canada Part II: weather trends from model forecasts. J. Glaciol., 10.1017/jog.2016.2

Conlan MJW and Jamieson B (2013) Weather preceding persistent deep slab avalanches. In Proceedings of the 2013 International Snow Science Workshop, 7-11 October 2013, Grenoble, FR, 219-226

Conlan MJW, Tracz D and Jamieson B (2014) Measurements and weather observations at persistent deep slab avalanches. Cold Reg. Sci. Technol., 97, 104-112 (doi: 10.1016/j.coldregions. 2013.06.011)

Conway H and Raymond CF (1993) Snow stability during rain. J. Glaciol., 39(133), 635-642

Davis ED, Elder K, Howlett D and Bouzaglou E (1999) Relating storm and weather factors to dry slab avalanche activity at Alta, Utah, and Mammoth Mountain, California, using classification and regression trees. Cold Reg. Sci. Technol., 30(1-3), 79-89 (doi: 10.1016/S0165-232X(99)00032-4)

de Quervain MR (1958) On metamorphism and hardening of snow under constant pressure and temperature gradient. IAHS AISH Publication, 46, 225-239

Exner T and Jamieson B (2008) Can solar warming contribute to dry slab avalanches? Avalanche J., 84, 70-73

Ferguson SA, Moore MB, Marriott RT and Speers-Hayes P (1990) Avalanche weather forecasting at the Northwest Avalanche Center, Seattle, Washington, U.S.A. J. Glaciol., 36(122), $57-66$

Fitzharris BB (1987) A climatology of major avalanche winters in Western Canada. Atmos.-Ocean, 25(2), 115-136 (doi: 10. 1080/07055900.1987.9649267)

Floyer JA (2012) A mechanism for cooling-related slab avalanche release. In Proceedings of the 2012 International Snow Science Workshop, 16-21 September 2012, Anchorage, AK, 252-255

Föhn P, Stoffel M and Bartelt P (2002) Formation and forecasting of large (catastrophic) new snow avalanches. In Proceedings of the 2002 International Snow Science Workshop, 29 September to 4 October 2002, Penticton, BC, 141-148

Föhn PMB (1980) Snow transport over mountain crests. J. Glaciol., 26(94), 469-480

Hachikubo A and Akitaya E (1997) Effect of wind on surface hoar growth on snow. J. Geophys. Res.-Atmos., 102(D4), 43674373 (doi: 10.1029/96jd03456)

Haegeli P and McClung DM (2007) Expanding the snow-climate classification with avalanche-relevant information: initial description of avalanche winter regimes for southwestern Canada. J. Glaciol., 53(181), 266-276 (doi: 10.3189/ 172756507782202801)

Hendrikx J, Owens I, Carran W and Carran A (2005) Avalanche activity in an extreme maritime climate: the application of classification trees for forecasting. Cold. Reg. Sci. Technol., 43(1-2), 104-116 (doi: 10.1016/j.coldregions.2005.05.006)

Hendrikx J, Murphy M and Onslow T (2014) Classification trees as a tool for operational avalanche forecasting on the Seward Highway, Alaska. Cold Reg. Sci. Technol., 97, 113-120 (doi: 10.1016/j.coldregions.2013.08.009)

Jamieson B (2006) Formation of refrozen snowpack layers and their role in slab avalanche release. Rev. Geophys., 44, RG2001 (doi: 10.1029/2005RG000176)

Jamieson B, Beglinger R and Wilson D (2014) Case study of a large snow avalanche in the Selkirk Mountains and reflections on the Canadian size classification. In Proceedings of Geohazards6, 15-18 June 2014, Kingston, ON, 8 pp

Jamieson JB, Geldsetzer T and Stethem C (2001) Forecasting for deep slab avalanches. Cold Reg. Sci. Technol., 33, 275-290 (doi: 10.1016/S0165-232X(01)00056-8) 
Jóhannesson T and Jónsson T (1996) Weather in Vestfirðir before and during several avalanche cycles in the period 1949 to 1995. Vedurstofa Íslands Internal Report VÍ-G96015-UR15, 8 pp (doi: 10.1002/j.1477-8696.1996.tb06149.x)

Jomelli V and 7 others (2007) Probabilistic analysis of recent snow avalanche activity and weather in the French Alps. Cold Reg. Sci. Technol., 47, 180-192 (doi: 10.1016/j.coldregions.2006. 08.003)

Jones AST and Jamieson B (2001) Meteorological forecasting variables associated with skier-triggered dry slab avalanches. Cold Reg. Sci. Technol., 33, 223-236 (doi: 10.1016/S0165-232X(01) 00040-4)

Judson A and Erickson BJ (1973) Predicting avalanche intensity from weather data: a statistical analysis. U.S. Rocky Mountain Forest and Range Experiment Station, Fort Collins, CO, USDA Forest Service Research Paper RM-112, 12 pp

Klock R and Mullock J (2001) The weather of British Columbia Graphic Area Forecast 31, Meteorological Service of Canada, Nav Canada, 221 pp

Kruskal WH and Wallis WA (1952) Use of ranks in one-criterion variance analysis. J. Amer. Statist. Assoc., 47(260), 583-621 (doi: 10.1080/01621459.1952.10483441)

Liston GE and Elder K (2006) A meteorological distribution system for high-resolution terrestrial modeling (MicroMet). J. Hydrometeorol., 7, 217-234 (doi: 10.1175/jhm486.1)

Mann HB and Whitney DR (1947) On a test of whether one of two random variables is stochastically larger than the other. Ann. Math. Stat., 18(1), 50-60 (doi: 10.1214/aoms/1177730491)

Marienthal A, Hendrikx J, Birkeland K and Irvine KM (2014) Meteorological variables associated with deep slab avalanches on persistent weak layers. In Proceedings of the 2014 International Snow Science Workshop, 29 September to 3 October 2014, Banff, AB, 21-28

McClung DM and Schweizer J (1999) Skier triggering, snow temperatures and the stability index for dry slab avalanche initiation. J. Glaciol, 45(150), 190-200 (doi: 10.3189/ 002214399793377121)

McClung DM and Tweedy J (1993) Characteristics of avalanching: Kootenay Pass, British Columbia, Canada. J. Glaciol., 39(132), $316-322$
Meiman JR (1968) Snow accumulation related to elevation, aspect and forest canopy. In Proceedings of the Workshop seminar in Snow Hydrology, Canadian National Committee for the International Hydrological Decade, Ottawa, ON, 35-47

Perla RI (1970) On contributory factors in avalanche hazard evaluation. Can. Geotech. J., 7(4), 414-419

Savage S (2006) Deep slab avalanche hazard forecasting and mitigation: the south face at Big Sky ski area. In Proceedings of the 2006 International Snow Science Workshop, 1-6 October 2006, Telluride, CO, 483-490 (doi: 10.1139/t70053)

Schirmer M, Wirz V, Clifton A and Lehning M (2011) Persistence in intra-annual snow depth distribution: 1. Measurements and topographic control. Water Resour. Res., 47(9), W09516 (doi: 10.1029/2010WR009426)

Schneebeli M, Laternser M, Föhn P and Ammann W (1997) Wechselwirkungen zwischen Klima, Lawinen und technischen Massnahmen. Schlussbericht NFP 31. Verlag der Fachvereine, ETH Zurich, Zurich, Switzerland, $132 \mathrm{pp}$

Schweizer J, Jamieson JB and Schneebeli M (2003) Snow avalanche formation. Rev. Geophys., 41(4), 1016 (doi: 10.1029/ 2002RG000123)

Schweizer J, Michot G and Kirchner HOK (2004) On the fracture toughness of snow. Ann. Glaciol., 38(1), 1-8 (doi: 10.3189/ 172756404781814906)

Schweizer J, Stoffel L and Mitterer C (2009) On forecasting large and infrequent snow avalanches. Cold Reg. Sci. Technol., 59(2-3), 234-241 (doi: 10.1016/j.coldregions.2009.01.006)

Stewart RE and 10 others (1995) Winter storms over Canada. Atmos.Ocean, 33(2), 223-247 (doi: 10.1080/07055900.1995. 9649533)

Stoffel A, Meister R and Schweizer J (1998) Spatial characteristics of avalanche activity in an Alpine valley - a GIS approach. Ann. Glaciol., 26, 329-336

Tracz D (2012) Deep snow slab avalanches. (Master of Science thesis, Department of Civil Engineering, University of Calgary, Alberta, Canada) $214 \mathrm{pp}$

Wilcoxon F (1945) Individual comparisons by ranking methods. Biometrics Bull., 1(6), 80-83 (doi: 10.2307/3001968) 